\title{
Use of Multimedia in Punjabi Learning System Design
}

\author{
Neelam \\ College of Education, Chitkara University, Punjab, India
}

Email: neelam.verma@chitkara.edu.in

\section{ARTICLE INFORMATION}

Received: June 15, 2018

Revised: August 09, 2018

Accepted: August 24, 2018

Published online: September 03, 2018

Keywords:

Multimedia Packages, Traditional Learning,

Computer Based Learning, Punjabi Language.

DOI: https://doi.org/10.15415/iie.2018.62013

\begin{abstract}
In this technology era, students are becoming more efficient in coursework because of a better understanding of the subject materials due to the availability of multimedia packages that make teaching-learning an interesting process. In India, the scope of regional languages is limited only to their regions. Hence, more emphasis has been put on the use of Multimedia to develop the mother tongue. The development of instructional material using Multimedia in the Punjabi Language will help the teachers to procure and use these packages in classroom teaching, to make teaching interesting. Also, this will help the teachers to make a shift from traditional methods of teaching to new computerized methods. Due to this, students will able to retain the concepts for a long time as these methods have proved very effective in other courses too. Furthermore, films and print media also have a great contribution towards the technical teaching of these languages to promote the usage of regional languages at the National and International Level.
\end{abstract}

\section{Introduction}

The traditional methods of teaching are not sufficient for bringing effective learning in students. For operative and practical knowledge, computer-based learning is the stepping stone [1]. It is fascinating to use computers for education purpose. Teachers play an instrumental role in providing efficient information based on computer-aid to the students. The teacher needs to adopt methods of teaching that result in quick learning and better retention among the students [8]. It is generally observed that the teachers accept those methods of teaching which brings consistency during coursework instead of the learning styles followed by students. Though the traditional method is used in schools, yet it would be more effective to use visual aid as it retains the impression on mind for a longer period. Usually, our authorities expected from the students to sit, listen and take notes which is necessary to generate ethics and make them sociable [11]. According to different investigators, it is concluded that different techniques should be used by the teachers to seed the interest of learning in students. Thus, it imparts an impression of positivity towards the studies [2]. The lecture is a formal presentation of content by an educator for the subsequent learning in examinations by students. Nowadays, efforts are being made to extend the way of teaching that allows the students to access information in a more systematic, logical and effective manner [3]. This also helps the students to acquire more knowledge in limited period. In education, multimedia is an emerging field of research in which many researchers are contributing and supporting smart schools in the modern education system. Smart education imparts a positive impact on students and motivates them to treat the learning process as playing the game rather than cramming [10]. Findings reveal that the use of instructional strategies like multimedia presentation is an addition to the traditional teacher-directed methods [12]. The previous research studies stated that for the students of different age groups, different learning patterns should be deployed to make the concept crystal clear and develop in depth understanding [4]. Various instructional strategies to enhance the traditional strategies for producing the significant improvements in student's achievement and are listed below.

a. Usage of still graphics combined with audio in slideshow and filmstrip projections were pioneered in fifteens and sixteens. To exemplify, $16 \mathrm{~mm}$ film brought the ability to add motion to the presentation [25].

b. By providing an access to the teachers to use learning resources like multimedia, helps in the development of constructive concept [15]. Thus, it permit the teachers to pay attention in functioning on being a coordinator of learning of an individual [5].

c. The multimedia has had a strong impression on education to enhance the current existing curriculum. 
The communication medium - "Language" plays an important role in day to day life. Similarly, Mother's tongue plays a significant role in the life of every individual. One can shape his or her life in a more simple and effective manner with the use of mother tongue [28]. In India, there are many languages and sub-languages according to different regions. The mother tongue for the region of Punjab is Punjabi. The language medium of instruction is Punjabi in almost every part of government schools of the Northern region. Though, it is very easy for the Punjabi student to learn this language, yet students are bounded to follow the rules of learning via traditional methods in this technological era. It is one of the reasons that students cannot understand the concept of grammar which is the base of any language. Thus, investigator felt that multimedia packages are the best way to teach Punjabi language and easier way to communicate the effectiveness of using computers to students.

\section{Review of Literature}

Liu and Reed (1994), examined cognitive style and media selection in educational hypermedia programs. They preferred a hypermedia program to teach English to international students in which learners choose different presentation formats for supporting information about vocabulary. They found that filed dependents utilized the video vignettes more often than field independents, and preferred text-based presentations. Although the navigation and information presentation selections differed, field dependents and field independents did equally well on the spot test. Sara Aloraini (2012) concluded the impact of using a computer in the education system. Pre and Post measurements of a student's academic achievement test had done. Consequently, a significant difference between the different age groups were found.

Genc Osman IIhan and Sahin Oruc (2016) worked on the usage of multimedia for social studies and compared the results with the traditional methods. Sahalu Junaidu (2008) explored the content of multimedia and an instrumental role played by the animation. Researchers finally concluded that over a period of five years the performance of student's success rate is reaching the sky. S. Malik and A.Aggarwal (2012) defined multimedia to an educational technology tool by providing its various advantages over traditional study system followed by different academics. Almahboud (2001) investigated the attitudes toward computer usage and gender differences of sixth-grade students. They also examined the relationship between student's attitudes toward using computers, school motivation, empathy, creative tendencies, and study habits. The results were in favour of researchers. Statistically significant correlation between attitude toward the computer, school, motivation study habits, creative tendencies, empathy and achievement in the informatics field were found.

\section{Implications of Literature Review}

- Multimedia can be utilized in different academic subjects for enhancing the performance of a Learner.

- Multimedia can ease the distance learning by using E-Learning.

- Multimedia can provide students and educators with an endless possibility of quality teaching and learning.

- Irrespective of cognitive style, Multimedia results in better learning method for both genders.

\section{Limitations of Traditional Methods}

By the traditional method, we mean bookish learning in which there is no concern with the technical world [16]. The following are some issues which defines the need for enhancement in the vision of education.

a. Students are unable to understand the difficult subjects verbally [29].

b. Students tend to lose their interests from the study as they do not feel novelty in the content [30].

c. Students learn the content through role method due to lack of content clarity [27].

d. Students are not able to ingress concentration due to the traditional lecture method [32].

\section{Advantages of Computerized Method}

Computerized learning is the key point in the educational environment. The following are some important points that defines the benefits of computer-based learning.

a. With the help of computer-based learning, students can see the images of different objects as per their content [18].

b. Students can see the content in a sentential format with a systematic approach in the form of PowerPoint presentation [19].

c. In multimedia packages, students can also hear the voice that increases the retention level.

d. Concept and content clarity can be more.

e. The teacher can enhance the interest level of the students in the studies.

f. The stress level can be decreased at the time of examination [35].

g. The teacher can increase the creativity of the child and reduce the role of cramming [20]. 


\section{Elements of Multimedia}

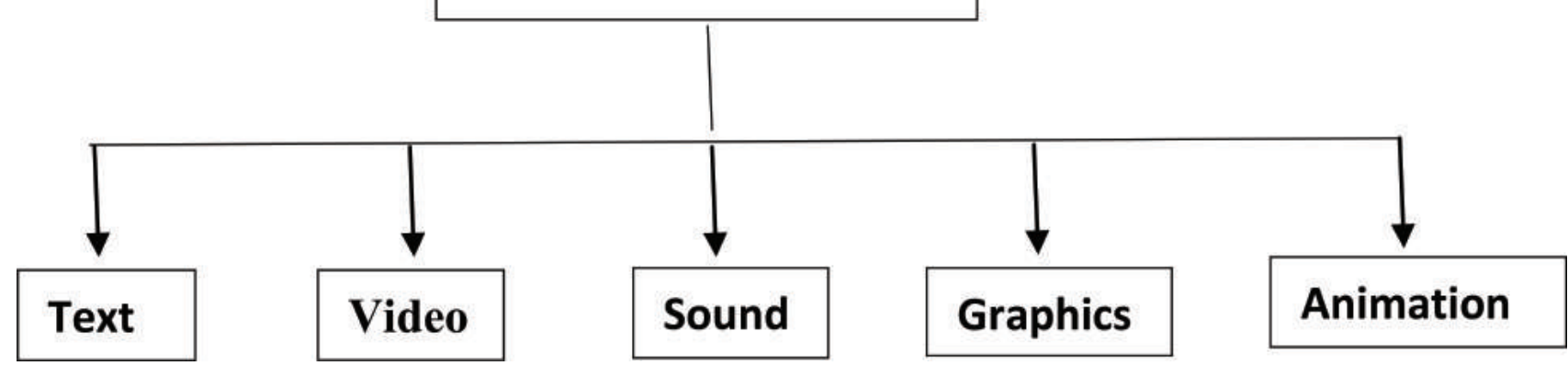

Figure 1: Elements of Multimedia.

\section{Techniques for Effective Language Learning}

\subsection{Multimedia}

Multimedia can be defined as the technology engaging in a variety of media, including texts, audio, video, graphics, and animation to communicate ideas. The interaction with these media presentation parameters should be designed carefully to control the tempo and direction of the information presented [33].

\subsection{Elements of Multimedia in Education}

There are several elements used in multimedia. By these multimedia elements technology provides a useful tool for both teachers and students [7]. An interactive multimedia has five basic types of media into the learning environment which is defined in figure 1.1

\subsubsection{Text}

The text is the keystone which combines all the media elements results in providing important information [24].

\subsubsection{Sound}

Sound when used creatively, becomes an incentive to the imagination and if used improperly becomes a glitch or barrier [22]. One can use still images with soundtracks and enhance the imagination. Thus, generates innovative mind. [26]

\subsubsection{Video}

Representing information by using the visual art of video can have a powerful and long-lasting impression. There is no doubt that video provides an ability to choose and define the view [23]. An interaction with the content of digital video provides interesting and animating possibilities to use digital video in education. It is likely to say that video lecture acts as a supplement to textual information, but we cannot say that it replaces the traditional lectures. The most imposing justification about video teaching is its dramatic behaviour in an emotional response from an individual. Thus, these kinds of efforts provide strong motivational appraisals to students [21].

\subsubsection{Animation}

The animation is the latest technique used to show changes in state over time or to present information slowly to students, so they have time to assimilate it in smaller chunks. Animations, when combined with user input, enable students to view different versions of change over time depending on different variables.

\subsubsection{Graphics}

Graphics provide the most creative possibilities for a learning session. It includes photographs, drawings, graphs from a spreadsheet, pictures from CD-ROM, or something pulled from the Internet [14]. With a scanner, hand-drawn work can also be included. Standing commented that, "the capacity of recognition memory for pictures is almost limitless". The reason for this is that images make use of a massive range of cortical skills: color, form, line, dimension, texture, visual rhythm, and especially imagination [7].

\section{Steps for Preparing Lessons to be Presented Through Multimedia}

In figure 1.2, the steps for preparing lessons to be presented through multimedia are shown using flow chart.

\subsection{Selection of the Content}

Investigator realized that the examples which are generally used to teach Punjabi grammar should be changed according to the level of interest and understanding of the students. To keep this point in mind investigator, select those types of examples which are different from the traditional content. Investigator selected 12 Units of grammar and divides the chapters according to the duration of the period. Thus, a total of 22 lessons were made from these 14 chapters. The tabular representation of the 14 chapters are deliberated below. 


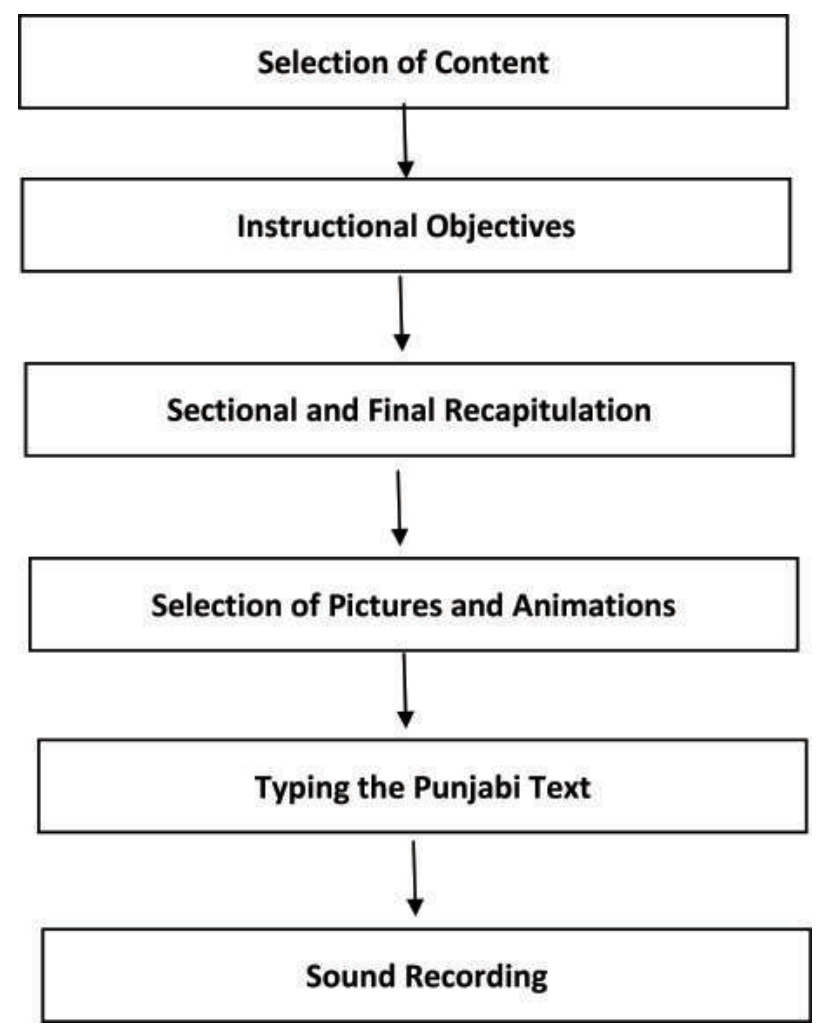

Figure 2: Flow Chart for Preparing the Lessons through Multimedia .

\begin{tabular}{ccc}
\hline Noun & Prepositions & Computer (Essay) \\
\hline Pronoun & Exclamatory Sentences & Computer (Essay) \\
Verb & Sentence & Pollution (Essay) \\
Adverb & Punctuation & \\
Adjective & Case & \\
Conjunction & Tense & \\
\hline
\end{tabular}

\subsection{Instructional Objectives}

After the selection of the content lesson investigator framed 4 to 6 instructional objectives of each chapter. It is simple aspect of life that if we want someone to follow the frame duties, one must need to engage into it. Similar is the case with students and teachers. Thus, instructions can be passed to students and the outcome achieved is the instructional objective. With the help of instructional objectives teachers can evaluate his/her own teaching style and judge the understanding level and creativity of student. In addition, the instructional objectives of chapter 1 is defined below.

- The students will be able to define noun in their own words without the help of teacher.

- The students will able to cite at least 5 examples of noun without the help of any reference material.
- The students will be able to identify and underline nouns in a paragraph by themselves.

- The students will be able to write the names of at least 3 kinds of noun without the help of any reference material.

- The students will be able to write at least 2 examples of each type of noun without the help any reference material with not more than two mistakes.

\subsection{Sectional and Functional Recapitulation}

Investigator wants to evaluate the understanding of content and framed sectional and final recapitulation. Those type of recapitulations were framed which were based on instructional objectives. So, that teacher can judge the content clarity of the lesson multimedia packages. To see the effectiveness of the content delivered investigator frame different type of questions according to the instructional objectives. Investigator could be able to judge those questions and hence they come to know about the understanding of the topic as per student perspective. Some of the questions framed are listed below according to the instructional objectives.

\section{Question 1: Define noun?}

Question 2: Give five examples of noun from your daily routine.

Question 3: From the paragraph, search the noun and underline it.

Question 4: Write any two types of noun.

Question 5: Give the two examples specific noun.

\subsection{Pictures and Animations}

After framing the examples from the grammar topics, investigator selected the appropriate pictures from the internet and some are animated by the investigator. In figure 1.3, an animated cartoon is repeating the word that is adverb.

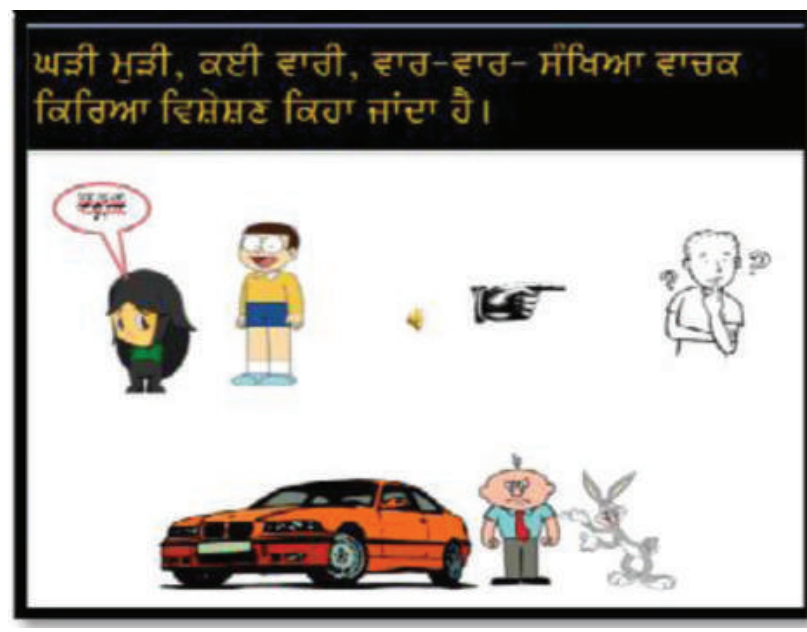

Figure 3: Adverbs in Punjabi Text. 


\subsection{Punjabi Text}

All the content for those multimedia packages were typed by the Punjabi instructor in the Punjabi language. In figure 1.4, animated Punjabi text has been shown which is easily retained by the learner.

\subsection{Sound Recording}

Investigator finally selects the pictures and content according to the lesson. The inbuilt modulated sound used in each power point presentation is with her voice only.

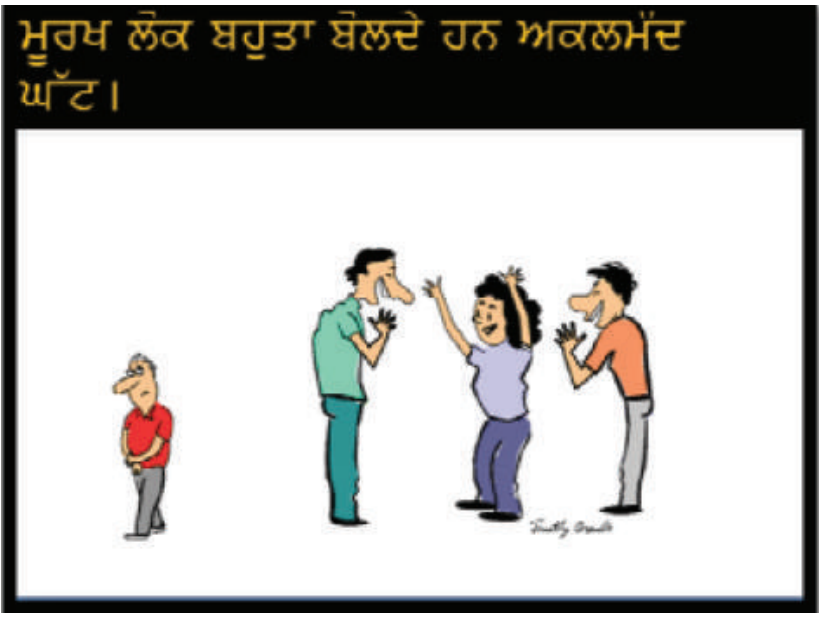

Figure 4. Adverbs Example in Punjabi text.

\section{Result Analysis}

Achievement test has been done on multimedia packages that is 22 lessons under the guidance of subject experts. The standardize sample of the questionnaire was made which include 60 questions out of 100 . The number of sample students taken for pre-test and post-test were 120. Finally, $2^{*} 2^{*} 2$ two-way factorial experimental research design can be employed which comprised of analysis of Variance (ANNOVA) and group statistics. The following graph depicts, several student $(\mathrm{N})$, mean and standard deviation with respect to pre-test and post- test. It can be analysed that the sample number of students $(\mathrm{N})$ taken a re same in both cases. On the contrary, mean and standard deviation in group statistics and ANNOVA during pre-test is showing into the mirror images having the mean value of 27.47 and standard deviation 4.282 whereas there is a significant rise in mean and standard deviation that is 50.97 and 3.287 respectively. Thus, it can be concluded that using multimedia packages in a class environment, not only raise the interest of students in studies but also doubled the performance of an individual to a higher extent.

\section{Conclusions \& Future Work}

In the end, we concluded that with the help of multimedia packages one can accelerate the evolution of Punjabi language not only in India but in foreign countries too. In the technological era, the Punjabi community of India

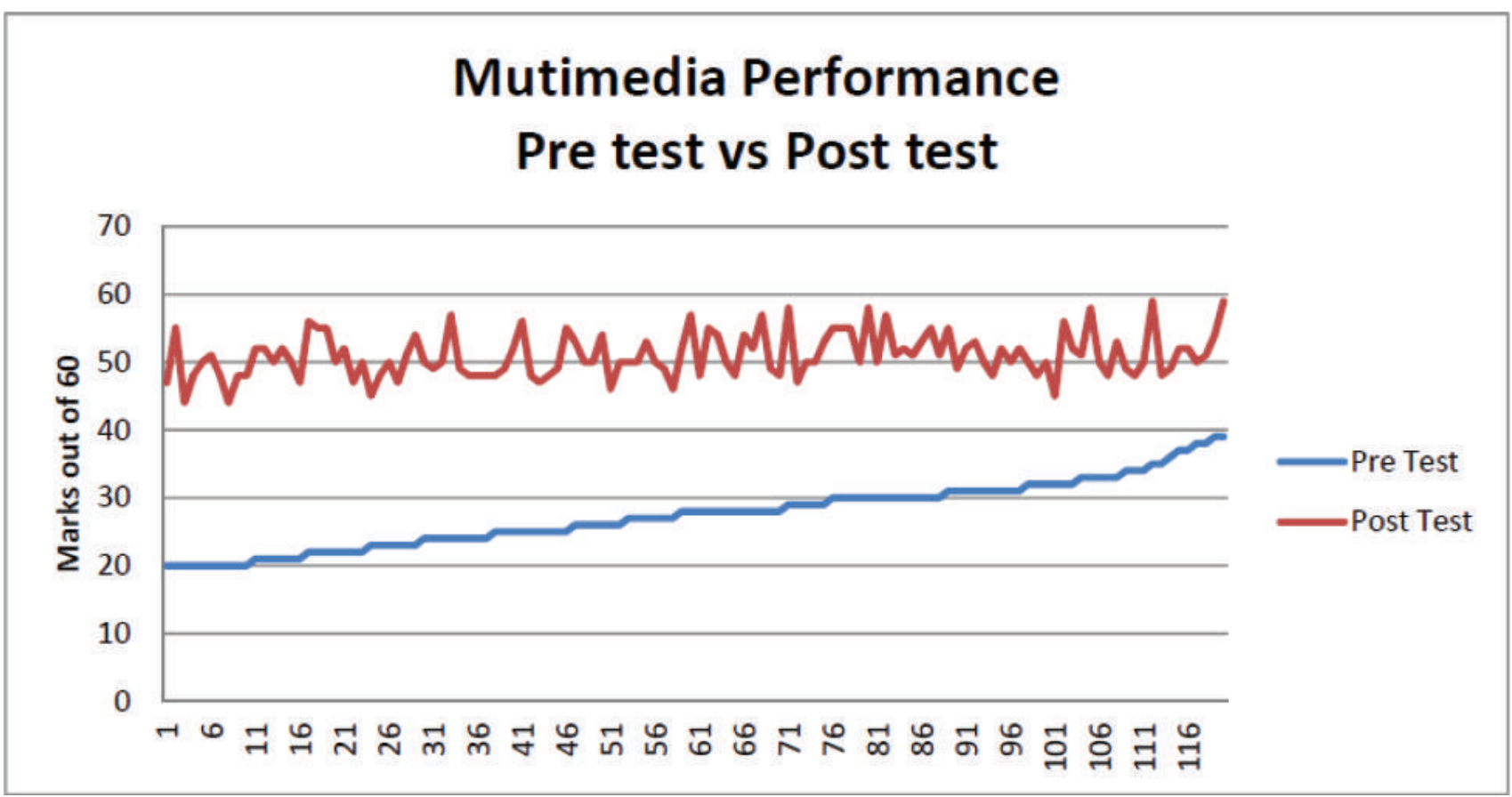


is spread across the globe. To provide the feel of mother tongue learning the Punjabi language is important to educate them through multimedia packages. Investigator chooses grammar topics initially because through these lessons students can understand the basic guidelines of a language. In future work, we will work on Concept Maps with the Punjabi Language to define the difference between the statistical analyses of the mental ability of students.

\section{References}

Husbands, C. (2011). Facilitating effective student learning through teacher research and innovation, Teacher Development, Taylor \& Francis, 401-402.

Aspray, W. (2016) Recent Efforts to Broaden Formal Computer Science Education at the K-12 Level Participation in Computing, Springer.

A. A. (2016). Five Powerful Ideas About Technology and Education New Developments in Science and Technology Education, Springer.

Abdullah, R. B. B. (2016). Inculcation of Malay Values and Culture in Language Pedagogy in Singapore Quadrilingual Education in Singapore, Springer.

Ahmad, M.; Rahim, L. A. \& Arshad, N. I. (2015). A multidomain framework: A qualitative study evolving understanding of subject-matter in modelling educational games Technology Management and Emerging Technologies (ISTMET), International Symposium, 384-389.

Akhtar, S. A.; Warburton, S. \& Xu,(2013).W. Development and Preliminary Evaluation of an Interactive System to Support CAD Teaching Multimedia (ISM), IEEE International Symposium, 480-485.

Ames, C. and Archer, J. (1988). Achievement goals in the classroom: Students' learning strategies and motivation processes. Journal of educational psychology, American Psychological Association, 80, 260.

Bidwell, N. J. (2016). Moving the centre to design social media in rural Africa AI \& SOCIETY, Springer 51.

Beynon, M. and Roe, C. (2004). Computer support for constructionism in context Advanced Learning Technologies, Proceedings. IEEE International Conference 216-220.

Basak, H. H. and Ozansoy, K. (2012). Comparison of traditional over WEB-Based Education: Case study "Adobe Flash "Information Technology Based Higher Education and Training (ITHET), International Conference, 1-8.

Banu, R. K. and Ravanan, R (2011). Analysis of e-learning in data mining --- A dreamed vision for empowering rural students in India Recent Trends in Information Technology (ICRTIT), International Conference, 12651270.

Billett, S. (2001). Learning in the workplace: Strategies for effective practice. ERIC.

Bryant, D. P.; Bryant, B. R. \& Smith, D. D. (2016). Teaching students with special needs in inclusive classrooms SAGE Publications.

Boyer, E. L. (1983). High school: A report on secondary education in America. ERIC.

Cardia, N.; Alves, R.; Gomes, A. and Mourão, A. (2016). Home Visitation Programs for Early Child Development: Experiences in Latin America and the Caribbean Home Visitation Programs, Springer.

Chamot, A. U. \& Kupper, L (1989). Learning strategies in foreign language instruction Foreign language annals, Wiley Online Library, 13-22.

Copeland, L. \& Gedeon, T. (2015). Tutorials in eLearning; How Presentation Affects Outcomes IEEE Transactions on Emerging Topics in Computing, PP.1

Deng, W. (2014). The English learning system design based on the Android platform Advanced Research and Technology in Industry Applications (WARTIA), IEEE Workshop, 777-780.

English, K. (2011). Teaching students with special needs in general education classrooms.

Hendricks, C. C. (2016). Improving schools through action research Pearson.

Laurillard, D. (2013). Rethinking university teaching: A conversational framework for the effective use of learning technologies Routledge.

Lewis, R. B.; Wheeler, J. J. and Carter, S. L. (2016). Teaching students with special needs in general education classrooms Pearson.

Misra, R.; Srivastava, S. and Abeles, T. (2016). M-education in India: an effort to improve educational outcomes with a special emphasis on Ananya Bihar On the Horizon, Emerald Group Publishing Limited, 24.

Okamoto, T. (2000). RAPSODY: distance ecological model for self- and collaborative-learning Advanced Learning Technologies. IWALT ,Proceedings. International Workshop 249-250.

Pintrich, P. R. and De Groot, E. V. (1990). Motivational and self-regulated learning components of classroom academic performance. Journal of educational psychology, American Psychological Association, 82, 33

Ponnuswamy, I. and Manohar, H. L. (2016). Impact of learning organization culture on performance in higher 
education institutions Studies in Higher Education, Taylor \& Francis, 41, 21-36

Stamovlasis, D. (2016). Catastrophe Theory: Methodology, Epistemology, and Applications in Learning Science Complex Dynamical Systems in Education, Springer.

Zoller, U. (2016). From Algorithmic Science Teaching to "Know" to Research-Based Transformative Inter-
Transdisciplinary Learning to "Think": Problem Solving in the STES/STEM and Sustainability Contexts Insights from Research in Science Teaching and Learning, Springer. 